\title{
AC 2007-235: ASSESSMENT OF LABVIEW AND MULTISIM IN THE DELIVERY OF ELECTRONICS LABORATORY CONTENT
}

\section{Julio Garcia, San Jose State University}

Dr. Julio Garcia is a Professor in the Department of Aviation and Technology in the College of Engineering at SJSU. He teaches electronics and computer courses to undergraduate students and graduate classes in the MS of Quality Assurance.

\section{Patricia Backer, San Jose State University}

Patricia Backer is a Professor and chair of the Department of Aviation and Technology in the College of Engineering at SJSU. She holds a BS degree in Chemical Engineering from Rutgers University, a MA and MS degree from Tennessee Temple University, and a MA and PhD from Ohio State. Her research interests are in the integration of multimedia and web-based learning into technology instruction. 


\title{
Assessment of LabVIEW and Multisim in the delivery of electronics laboratory content
}

\begin{abstract}
The goal of this study, funded by the National Science Foundation, was to adapt the work of other researchers to improve the delivery of electronics lecture and laboratory content in the Electronics \& Computer Technology (ECT) area. From the extensive research on ethnic and gender differences in learning styles, the evidence suggests that ethnic minorities and women work best when the material is organized so that students work in teams and have a high level of hands-on experimentation and problem-solving. We developed our materials to maximize these aspects since in our institution the "minority" constitutes the majority of our student body. This project created online lecture and laboratory materials for Tech 167-Control Systems, an upper division electronics course using Multisim and LabVIEW.
\end{abstract}

The laboratory content of the course Tech 167 "Control Systems" has been revised. As a result, ten lab experiments were completed and pilot tested using Multisim, a computer simulation program. If the observations of the students who have tested these lab experiments in fall 2005 are an indication, there is no doubt that students who performed these experiments in groups learned more and were also able to provide meaningful feedback to improve them. The ten lab experiments were refined based on students' feedback and were performed by all students enrolled in Tech 167 "Control System" in the fall 2006 semester. A kit containing all the components needed to perform the ten lab experiments was provided to each student. In this way, students were able to first use computer simulation for each lab experiment and then hardwire them using the kit. After comparing the results of the computer-simulated and the hardwired experiments, we found no significant differences in student achievement. However, there appears to be a difference in attitudinal measures. Students who used both the computer simulations and hardwired experiments reported that that they learned the material better.

Students completed a pre-test and posttest of the Concept Inventory test. In addition, students took the General Attitudes Toward Computers test, Computer Thoughts Survey and the Computer Anxiety Rating test.

\section{Introduction}

The overarching goal of this curriculum improvement project was to use the work of other researchers to improve the delivery of electronics lecture and laboratory content in the Electronic \& Computer Technology (ECT) area of the BS in Industrial Technology at San Jose State University, San Jose California, USA. The five objectives for this project were:

1. Revise the lecture and laboratory content for Tech 167-Control Systems in line with theories of effectiveness in web-based instruction ${ }^{1,2,3}$

2. Develop multimedia lecture materials for the teaching/learning of Tech 167 -Control Systems using $\mathrm{WebCT}^{4}$ 
3. Revise the laboratory activities to integrate an electronics kit (consisting of data acquisition hardware) so that students can complete them following the model established by Wang 5

4. Adapt the curriculum materials in line with research on learning styles of women and minority students

5. Integrate LabVIEW and Multisim in the Tech 167 class to provide the students with realistic, industry-based simulation experiences

\section{Problem addressed in this project}

The Department of Aviation and Technology at San Jose State University (SJSU) offers two bachelor's degrees: BS in Industrial Technology (BSIT) and BS in Aviation. The BSIT has two concentrations: Electronics and Computer Technology (ECT) and Manufacturing Systems. The students are not distributed equally between the two concentrations; $33 \%$ of BSIT majors are Manufacturing Systems students and 67\% are Electronics and Computer Technology (BSITECT) majors. This inequity is not surprising considering the location of the university in Silicon Valley, CA. The university, as a whole, has large enrollments in electronics and computerrelated fields including computer engineering, computer science, MIS, and the BSIT-ECT.

Table 1. Fall 2005 Distribution of BSIT majors by Gender and Ethnicity as compared to SJSU numbers

\begin{tabular}{|l|r|r|r|r|r|r|r|r|r|}
\hline & Total & $\begin{array}{r}\text { African } \\
\text { American }\end{array}$ & Hispanic & Asian & Filipino & Other & $\begin{array}{r}\text { Total } \\
\text { Minority }\end{array}$ & White & Unknown \\
\hline $\begin{array}{l}\text { Female } \\
\text { BSIT }\end{array}$ & $\mathbf{1 7}$ & $\mathbf{1}$ & $\mathbf{1}$ & $\mathbf{1 1}$ & $\mathbf{1}$ & $\mathbf{0}$ & $\mathbf{1 4}$ & $\mathbf{1}$ & $\mathbf{2}$ \\
\hline $\begin{array}{l}\text { Male } \\
\text { BSIT }\end{array}$ & $\mathbf{1 5 4}$ & $\mathbf{5}$ & $\mathbf{1 8}$ & $\mathbf{6 4}$ & $\mathbf{2 0}$ & $\mathbf{2}$ & $\mathbf{1 0 9}$ & $\mathbf{2 7}$ & $\mathbf{1 6}$ \\
\hline $\begin{array}{l}\text { Total } \\
\text { BSIT }\end{array}$ & $\mathbf{1 7 1}$ & $\begin{array}{r}\mathbf{6} \\
\mathbf{( 3 . 5 \% )}\end{array}$ & $\begin{array}{r}\mathbf{1 9} \\
(\mathbf{1 1 \%})\end{array}$ & $\begin{array}{r}\mathbf{7 5} \\
\mathbf{( 4 3 \% )}\end{array}$ & $\begin{array}{r}\mathbf{2 3} \\
\mathbf{( 1 3 \% )}\end{array}$ & $\begin{array}{r}\mathbf{2} \\
(\mathbf{1 \%})\end{array}$ & $\begin{array}{r}\mathbf{1 2 5} \\
\mathbf{( 7 3 \% )}\end{array}$ & $\begin{array}{r}\mathbf{2 8} \\
(\mathbf{1 6 \%})\end{array}$ & $\begin{array}{r}\mathbf{1 8} \\
(\mathbf{1 0 \%})\end{array}$ \\
\hline $\begin{array}{l}\text { SJSU } \\
\text { Total } \\
\text { UG }\end{array}$ & $\mathbf{2 2 7 3 3}$ & $\begin{array}{r}\mathbf{1 1 4 8} \\
\mathbf{( 5 \% )}\end{array}$ & $\begin{array}{r}\mathbf{3 6 8 6} \\
(\mathbf{1 6 \%})\end{array}$ & $\begin{array}{r}\mathbf{6 8 7 8} \\
\mathbf{( 3 0 \% )}\end{array}$ & $\begin{array}{r}\mathbf{2 0 1 0} \\
(\mathbf{9 \%})\end{array}$ & $\begin{array}{r}\mathbf{3 1 0} \\
(\mathbf{1 \%})\end{array}$ & $\begin{array}{r}\mathbf{1 4 0 3 2} \\
\mathbf{( 6 1 \% )}\end{array}$ & $\begin{array}{r}\mathbf{5 6 6 6} \\
(\mathbf{2 5 \%})\end{array}$ & $\begin{array}{r}\mathbf{3 0 3 5} \\
(\mathbf{1 3 \%})\end{array}$ \\
\hline
\end{tabular}

There are several other demographic factors that serve to make the delivery of instruction challenging for the department. Approximately $70 \%$ of ECT students work at least 30 hours a week. In addition, the BSIT program is also unique in that it is primarily a transfer program. Most of the students in the BSIT degree are transfer students from local community colleges and $88 \%$ of the majors are classified as juniors or seniors. Also, most of the BSIT students attend SJSU part-time as they finish their degrees. These transfer students generally spend between four to five years at SJSU finishing their BSIT degree after they transfer from a two-year community college. SJSU also has a diverse student population (see Table 1) with $61 \%$ of all undergraduates identified as having non-White ethnicity. A higher percentage $(73 \%)$ of the undergraduate students in the BSIT is non-White and there are significantly more students from Asian and Filipino backgrounds in the BSIT than in the university as a whole. This could be significant, as previous research has indicated that the ethnicity of the students could interact with their learning styles. Studies indicate that Asian students have different learning styles than Caucasian students do ${ }^{6}$. 
The large numbers of working students in the ECT concentration make the scheduling of classes with laboratories a significant problem. All upper division courses in the ECT concentration are offered once a year and courses shift bi-annually from day to night rotation. Students who work often must wait a year to take a required course that meets with their schedule. The high number of non-native speakers of English in the ECT concentration makes traditional lectures difficult to deliver.

\section{Curriculum Development}

This project developed online lecture and laboratory materials for Tech 167--Control Systems, an upper division ECT course, whose description is as follows:

Tech 167. Theory and applications of feedback systems, transfer functions and block diagrams. Transducers, analog and digital controllers, signal conditioners, and transmission. Analysis, testing, and troubleshooting of electronic systems with feedback. Prereq: Tech 62, Tech 63, Math 71, Tech 115.

Although an upper division course, Tech 167 is typically taken by ECT students during their first year after transfer from a local community college. Students have had basic electronics, basic analog electronics, basic digital electronics analysis, and an instrumentation course before registering for this course. This curriculum project converted the lecture content of Tech 167 into WebCT lectures that were delivered to the students in an asynchronous mode. This innovation addressed two issues. Working students can take this course early in their SJSU career. Also, students from non-English speaking backgrounds can complete the lecture materials at their own pace.

Hundreds of courses have been developed for delivery using WebCT as a medium for online instruction but few are available for electronics courses. Since many electronics courses include a laboratory or hands-on component, it is challenging to develop the complete course through distance education. Sharer and Frisbee ${ }^{4}$ developed a junior level microelectronics course entitled Active Networks I for the Electrical emphasis in the Engineering Technology Department at the University of North Carolina-Charlotte. They used a variety of synchronous and asynchronous delivery methods. Their asynchronous WebCT site for this course included a detailed course syllabus, a course schedule, lecture notes, examples, homework solutions, test solutions, and computer simulations. These researchers used Centra for synchronous delivery for problems sessions and electronic supplemental instruction.

These researchers found that the students liked the delivery of the course through distance education. Similar to the student population at San Jose State, the students at UNC-Charlotte are generally non-traditional and have full time employment and family obligations. The online microelectronics WebCT class ${ }^{4}$ was used as the model for the lecture portion of this project's curriculum development. Instead of Centra, this project used Microsoft NetMeeting as the mechanism for student-teacher problem sessions. Each week, the instructor of this class was available for several hours to answer student questions in a synchronous format. 
The demographics of the diverse student population in the Electronics Technology area at SJSU is a good match for learning through distance education. Most of the students in this area are part-time, older, and working 30-40 hours a week. They tend to be self-sufficient and selfdirected. These characteristics have been proven to be descriptors of successful distance learners ${ }^{7,8}$.

The multimedia lecture materials helped students understand control systems concepts, circuit and systems analyses, and problem solving of control systems related material. Concepts such as analog and digital signal conditioning, thermal sensors, optical sensors, and controllers were emphasized. Procedures for designing control circuits as well as systems analyses were included. The web-based multimedia learning materials consisted of text, graphics, and animations integrated into a WebCT course site. The web-based lecture materials were designed to ameliorate known problems with web-based learning. In particular, Sharer and Frisbee ${ }^{4}$ note that several considerations exist for successful completion of web-based courses. These considerations for engineering-related instruction include, but are not limited to: more selfdiscipline is required to get through lecture material than in a traditional class; the student does not have the benefit of face-to-face interaction with the instructor; and communication between student and instructor is not immediate and requires more planning ${ }^{9,10,11}$.

The laboratory exercises for Tech 167 were redesigned to use LabVIEW, Multisim, and digital acquisition equipment. This project used the SC-2075 Prototyping Signal Accessory Box with the NI PCI-6024E DAQ and the R6868 Ribbon Cable manufactured by National Instruments. The SC-2075 is a connector accessory for constructing circuits and evaluating the circuits using virtual instruments. The kit consisted of all the components and devices needed for students to build ten laboratory exercises. The students can reuse these materials to perform other experiments related to control systems and industrial electronics as well as design and build a control system project.

This project used LabVIEW software (Laboratory Virtual Instrument Engineering Workbench) integrated with data acquisition equipment to provide a virtual electronics laboratory for students. First developed in 1983 by National Instruments, LabVIEW has become a standard tool for engineers and scientists. LabVIEW is a powerful graphical development program for signal acquisition, measurement analysis, and data presentation. Data acquisition (DAQ) involves connecting computers to a wide variety of gadgets via electronic signals; the computers then control these gadgets or read data from these gadgets.

Along with the $\mathrm{C} / \mathrm{C}++$ programming languages, LabVIEW is among the most used programming languages for technical and scientific applications today, used to solve technical and commercial problems. LabVIEW's programming features are clear, coherent, powerful, comprehensive and entertaining, enabling an instructional presentation of computer-based experimentation in which students create meaningful programs that illustrate useful concepts at each step of the learning curve. LabVIEW programs are modular, so that after each is created and understood, it becomes part of a library that can be used later as a building block of a more sophisticated program.

Lee $^{12}$ integrated LabVIEW software into an instrumentation and experimental methods course for mechanical engineering students. Other researchers have developed LabVIEW applications 
for students in agricultural and biological engineering ${ }^{13}$, mechanical and industrial engineering ${ }^{14}$, and engineering technology ${ }^{15,16,17,18,19}$.

Wang $^{5}$ developed a series of LabVIEW modules to use in sophomore electrical circuits and mechanical mechatronics laboratory courses at West Virginia University. Students are able to measure the voltage, temperature changes by using LabVIEW, see the real time responses from the computer screen, and switch controls between computers through the Internet.

In the past ten years, companies have developed several interfaces for computer-based electronics simulation. The SC-2075, for example, is used widely in industrial settings for the control and testing of a variety of electronics-based applications. Digital acquisition equipment produced by National Instruments has also been used in academic settings. Stevens Institute of Technology uses a microcomputer-based data acquisition system with LabVIEW and MatLab software in the laboratories that support their expanded design course sequence. Chickamenahalli, Nallaperumal, and Waheed ${ }^{20}$ used a data acquisition board produced by National Instruments to develop a real-time visual controller for manufacturing processes as part of an NSF funded Greenfield Coalition's Manufacturing Engineering curriculum development program.

To ensure students' understanding of computer simulation, students performed these experiments using Multisim 7 (fall 2005) and Multisim 8 (fall 2006), a power computer simulation software widely used in industry. Students compared the measurements obtained using Multisim and using real devices and components, and compared the values obtained using LabVIEW. Multisim is a comprehensive circuit analysis program that permits the modeling and simulation of electrical and electronic circuits. It provides a large component database, schematic entry, analog/digital circuit simulation, and many other features, including seamless transfer to printed circuit board (PCB) layout packages. Multisim is interactive and offers a number of user-friendly features. A major feature of Multisim is that the schematic diagram is created on the screen using a mouse and various windows options. The type of analysis desired is then applied to the circuit, and the results can be observed in a number of ways.

One of the most valuables features of Multisim is that the source excitation and instrumentation functions closely parallel those of a basic electronics laboratory, and the procedures that are used in obtaining data are very similar to those of the "real world." Hence, it closely approaches the concept of an ideal "virtual laboratory." For example, the test and measurement models contain voltmeters, ammeters, a multimeter, a function generator with several output waveforms, a twochannel oscilloscope, a frequency counter, a distortion analyzer, and other instruments. These instruments must be wired into the circuit in essentially the same fashion as in an actual laboratory. Thus, good laboratory skills can be taught very easily using a computer and the software.

Hackworth and Stanley ${ }^{21}$ used Multisim in the development and implementation of a junior-level virtual linear electronics laboratory at Old Dominion University. All experiments and projects in the virtual laboratory course are analogous to the experiences in the on-campus traditional course. The researchers found that the virtual laboratory was as effective as the traditional laboratory in terms of student achievement. At Northwestern State University, Hall ${ }^{22}$ compared 
groups of students who were enrolled in two different electronics courses, a basic DC circuits laboratory course and an advanced device electronics laboratory course. He found that there were no significant differences in posttest scores between students using Multisim and those performing the labs using traditional lab equipment.

This project used LabVIEW, Multisim and the SC-2075 data acquisition device to create virtual laboratories for Tech 167--Control Systems (see Table 2 for a description of the ten laboratories that were developed). This project included student assistants from the ECT concentration who assisted in the development and assessment of the web-based lecture and virtual laboratory modules. In addition to the formative assessment of these modules by the student assistants, these online laboratories were field-tested in the fall 2005 and fall 2006, Tech 167 class. The PIs chose four labs and randomly assigned student teams to either the online laboratory or the traditional lab using electronic equipment. The student assistants videotaped a sample of the student teams so that there was a record of the students' behaviors as they completed the labs. The PIs and the student assistants analyzed the videotaped records and this information was used to further refine the online laboratories.

\section{Table 2. Laboratory Experiments That Were Developed}

\begin{tabular}{|l|l|}
\hline Lab & Topic \\
\hline 1 & Wheatstone Bridge \\
\hline 2 & Analog Signal Conditioning \\
\hline 3 & Digital Signal Conditioning \\
\hline 4 & SCR/TRIAC Circuits \\
\hline 5 & Sensors and transducers \\
\hline 6 & Proportional Controller \\
\hline 7 & Integral Controller \\
\hline 8 & Derivative Controller \\
\hline 9 & PID Controller \\
\hline 10 & Closed-loop systems \\
\hline
\end{tabular}

\section{Activities and Findings}

The ten lab experiments were tested in Tech 167 during the fall 2005 and fall 2006 semesters. Students, working in groups of two, were given an electronic kit consisting of all the devices and components needed to complete the ten laboratory experiments. Students' feedback were that they were able to complete the lab assignments in less time because they didn't waste time finding the devices and components they needed as was experienced in the past. The lab manual was structured in such a way that students had to computer simulate the circuit, perform all the calculations, verify the circuit's behavior, and then hardwire it. In this way, students were able to learn Multisim and improve their circuit-building, testing and troubleshooting skills.

In addition, students were able to observe the behavior of each lab activity using LabVIEW supplemented with a short PowerPoint presentation. In this way, students were exposed to more than one teaching style. 
This is the final report on a three-year project to determine the effect on students in the Tech 167 course of implementing new electronics course materials. The measures that were used to assess these effects were

- The Student Assessment of Learning Gains administered three times each semester

- The Concepts Inventory test administered at the beginning and end of each semester

- Three tests of computer attitudes and technophobia: the General Attitudes toward Computers Scale (GATCS); the Computer Thoughts Survey (CTS); and the Computer Anxiety Rating Scale (CARS) These tests were each administered once during the semester

\section{Findings from the Student Assessment of Learning Gains test}

The students enrolled in the Tech 167 class in 2004, 2005 and 2006 completed the Student Assessment of Learning Gains (SALG) three times during the semester. The SALG was originally designed for assessing chemistry teaching and learning in over 100 two- and four-year institutions $^{24}$. The National Science Foundation funded this project for five years (1995-2000) as part of two, linked consortium, "ChemLinks" and "ModularChem." The SALG instrument was modified to meet the needs of this course. The SALG can be found at http://www.wcer.wisc.edu/salgains/instructor.

Scores from the SALG questionnaire were aggregated on an electronic data base using Zoomerang. Students were asked questions about how helpful the various aspects and resources of the class were in learning the material and how much they learned about some specific topics and problem solving and understanding in general. The project considers the SALG the strongest measure of success in meeting the project's goals.

The SALG consisted of five questions, four of which were multi-part. Averages were provided for each overall question, as well as for each individual part. Higher average scores corresponded to higher overall ratings by students. [For the results reported below a response of 3 represents "somewhat" and 4 represents "a lot".]

Overall results: There were differences in the way the data were reported for the three cohorts. For the 2004 and 2005 cohorts, the results from all three administrations of the SALG were aggregated; in 2006, the three sets of results were reported separately. For this reason only total scores for the three years will be compared. The total scores for the three years were

$\begin{array}{lll}\underline{2004} & \underline{2005} & \underline{2006} \\ 3.35 & 3.47 & 3.42\end{array}$

Compared to the baseline score of 3.35, the 2005 SALG scores showed an improvement of 3.6\% and the 2006 SALG showed an improvement of 2.1\%. The students enrolled in Tech 167 in Fall 
2005and Fall 2006 rated the class and their learning higher than the students enrolled in the class in Fall 2004 in some substantive ways.

A number of the questions on the SALG relate to particular aspects of the course (such as class activities and resources) and how these particulars contributed to student learning. These questions can provide valuable feedback to the instructor for future planning of courses. However, in terms of outcomes for the students, there are three questions which constitute better measures of what the students actually learned from the course and how valuable this new knowledge is likely to be after the students leave the class. Below are some results for three individual questions on the SALG which captured this type of knowledge. [Percentages represent only students responding to the question, not "N/A" responses.]

Question: How much of the following (understanding the main concepts) do you think you will remember and carry with you into other classes or aspects of your life?

\begin{tabular}{|l|c|c|c|}
\hline & $\mathbf{2 0 0 4}$ & $\mathbf{2 0 0 5}$ & $\mathbf{2 0 0 6}$ \\
\hline Average rating & 3.21 & 3.54 & 3.37 \\
\hline Percent of students rating "Somewhat" or better & $83 \%$ & $92 \%$ & $90 \%$ \\
\hline
\end{tabular}

Question: How much has this class added to your skills in each of the following: solving problems, writing papers, designing lab experiments, finding trends in data, critically reviewing articles, working effectively with others, giving oral presentations?

\begin{tabular}{|l|c|c|c|}
\hline & $\mathbf{2 0 0 4}$ & $\mathbf{2 0 0 5}$ & $\mathbf{2 0 0 6}$ \\
\hline Average rating & 3.32 & 3.38 & 3.25 \\
\hline Percent of students rating "Somewhat" or better & $80 \%$ & $87 \%$ & $86 \%$ \\
\hline
\end{tabular}

Question: To what extent did you make gains in any of the following as a result of what you did in this class: understanding the main concepts, understanding the relationship between concepts, understanding how ideas in this class relate to those in other science classes, understanding the relevance of this field to real world issues, appreciating the field, ability to think through a problem or argument, confidence in your ability to do this field, feeing comfortable with complex ideas, enthusiasm for subject?

\begin{tabular}{|l|c|c|c|}
\hline & $\mathbf{2 0 0 4}$ & $\mathbf{2 0 0 5}$ & $\mathbf{2 0 0 6}$ \\
\hline Average rating & 3.26 & 3.4 & 3.34 \\
\hline Percent of students rating "Somewhat" or better & $78 \%$ & $77 \%$ & $83 \%$ \\
\hline
\end{tabular}

Overall, students in all three cohorts indicated that they learned between "somewhat" and "a lot"., with substantial majorities of students in the "somewhat", "a lot", or "a great deal". Most of the measures shown above favor the 2005 and 2006 cohorts. These students reported greater learning gains, even though there were not great differences in the increases in Concept Inventory scores (see below).

Students' additional comments: Students were given an opportunity to make additional comments on the SALG. In 2004, the majority of these additional comments were positive. The 
2005 comments about the course and instructor were also positive. In contrast to the students in the 2004 and 2005 cohorts, very few students in 2006 offered additional comments. The few who chose to do so made positive comments, or constructive criticisms of the course, such as a suggestion to replace the textbook.

\section{Findings from the Concept Inventory}

In September 2005, thirty-two students enrolled in the Tech 167 course in the Department of Aviation and Technology took the Electronics Concept Inventory Pre-Test. This concept inventory was adapted from the one developed by Flores \& Fabela ${ }^{23}$. Of the thirty-two who took the pre-test, twenty-five also took the post-test at the end of the semester. For purposes of measuring improvement in the students' pre- and post-test scores, only scores for those students who took both tests will be considered.

\section{Comparison of Pre-Test and Post-Test Scores within the 2005 Cohort}

The pre-test scores of the twenty-five students taking both tests ranged from 21 points (42\%) to 33 points $(66 \%)$. The mean score for 24 of these students was $27.7(55.4 \%)$. The median score for these same students was $28(56 \%)$ and the three modal scores were 27,30 , and 31, with three students making each of these scores. Half (12) of the students scored between 25 and 31 . The maximum number of points was 50 .

The post-test scores of these students ranged from 9 points (18\%) to 37 points (74\%). The score of 9 points was clearly an outlier, the next lowest score being 20 points. The student making this score had scored 27 points on the pre-test; a drop of 18 points on this test seems anomalous. Therefore, the statistical measures for the 2005 cohort will be computed excluding this student's pre- and post-test scores. Half (12) of the students scored between 27 and 32.

\section{Comparison of Pre-Test and Post-Test Scores within the 2006 Cohort}

The pre-test scores of the nineteen students taking both tests ranged from 18 points (36\%) to 38 points $(76 \%)$. The mean score for these students was $28.9(57.8 \%)$. The median score for these same students was $29(58 \%)$ and the two modal scores were 29 and 31, with three students making each of these scores. Half (9) of the students scored between 26 and 31.

The post-test scores of these students ranged from 20 points (40\%) to 36 points (72). The mean score for the post-test was $28.2(57.6 \%)$ and the median score was $29(58 \%)$. The modal score was 32 (64\%), with five students earning this score. Half (9) of the students scored between 26 and 32 .

Compared to the pre-test, the modal score on the post-test increased. Other statistical measures showed insignificant differences between the two administrations of the Concepts Inventory. Overall, eight students showed increases of one to ten points between the pre- and post-test; nine students showed decreases of one to ten points; two students' scores were unchanged. 


\section{Comparison of Pre-Test and Post-Test Scores for the 2004, 2005, and 2006 Cohorts}

Table 3 shows the statistical measures of the pre-test and post-test scores for the three years. The "middle scores" are the range of scores within which half of the students' scores were found.

Table 3. Comparison of the student scores on the Pretest and Posttest for 2004, 2005 and 2006

\begin{tabular}{|l|c|c|c|c|c|c|}
\hline & \multicolumn{3}{|c|}{ Pretest } & \multicolumn{3}{c|}{ Posttest } \\
\hline & 2004 & 2005 & 2006 & 2004 & 2005 & 2006 \\
\hline Min-max scores & $19-39$ & $21-33$ & $18-38$ & $17-45$ & $20-37$ & $20-36$ \\
\hline Middle scores & $23-38$ & $25-31$ & $26-31$ & $26-33$ & $27-32$ & $26-32$ \\
\hline Mean scores & 25.7 & 27.7 & 28.9 & 29.3 & 29.5 & 28.2 \\
\hline Median scores & 25 & 28 & 29 & 27 & 29 & 29 \\
\hline Modal score(s) & $23(6)$ & $27,30,31(3)$ & $29,31(3)$ & $27(5)$ & $27(5)$ & $32(5)$ \\
\hline Midrange & 29 & 27 & 28 & 31 & 28.5 & 28 \\
\hline
\end{tabular}

Between the pre-test and the post-test, the mean score for 2005 increased by 1.8 points (or 3.6\%), compared to 3.6 points ( $7.2 \%$ ) for the 2004 cohort. The median score increased by 1 point, compared to 2 points in 2004. The modal score was lower than two of the 2004 modal scores. Overall, the pre-test and post-test scores were higher in 2005 than in 2004, but they showed less improvement.

Considering individual students' changes in test scores, fifteen of the twenty-four students (or $62.5 \%$ ) in 2005 improved their scores on the post-test from 3 to 11 points, similar to the $67.7 \%$ who showed improvement in 2004. Two students showed no improvement, while seven students made a lower score on the post-test than on the pre-test, with scores being lowered from 2 to 13 points (excluding the student whose score was lowered by 18 points). The most common increase in test scores was four points, with seven students showing this increase. The most common increase in test scores in 2004 was two points, with five students showing this increase.

The major difference between the 2004 and 2005 cohorts was that in 2004 five students improved their scores by more than the greatest improvement shown in 2005, with gains ranging from 13 to 23 points. These high performing students accounted for the higher mean and median scores for 2004.

As mentioned above, there was little change in the statistical measure between the pre- and posttest scores in 2006. The pre-test scores in 2006 were higher than those in 2004 and 2005, but they showed less improvement.

\section{Findings from the General Attitudes Toward Computers Scale (GATCS), Computer Anxiety Rating Scale (CARS) and Computer Thoughts Survey (CTS) tests}

Students in all three cohorts took three surveys at the beginning of the semester to assess their attitudes toward computers, including technophobia. These tests were the General Attitudes toward Computers Scale (GATCS), the Computer Thoughts Survey (CTS), and the Computer Anxiety Rating Scale (CARS). The scores for each question were interpreted according to "Measuring Technophobia" by Rosen and Weil. A composite score for each test for each cohort 
was computed by a method described in the Addenda section below. Weighting factors were used to compensate for the fact that fewer people took the surveys in $2005(\mathrm{n}=32)$ and in 2006 $(\mathrm{n}=25)$ than in $2004(\mathrm{n}=41)$.

The results are shown in Table 4. For the GATCS and CTS surveys, higher scores indicate more positive attitudes toward computers and technology. For the CARS survey, higher scores indicate more computer anxiety.

Table 4. Results of Computer Anxiety Surveys

\begin{tabular}{|l|l|l|l|}
\hline Year & GATCS & CTS & CARS \\
\hline 2004 & 2725 & 3095 & 1702 \\
\hline 2005 & 2583 & 3188 & 1582 \\
\hline 2006 & 2196 & 3172 & 1415 \\
\hline
\end{tabular}

So, the results of these surveys are mixed. The 2004 cohort of students showed a more positive attitude towards computers based on the GATCS, while the 2006 cohort showed the least positive attitude. However, the results were reversed on the CARS, with the 2004 cohort showing the most computer anxiety and the 2006 cohort showing the least. The scores on the CTS do not vary widely, but the 2005 and 2006 scores show a more positive attitude toward computers than the 2004 scores. Based on these scores, it is difficult to say that a particular year's cohort exhibited a greater or lesser degree or technophobia, or more positive or negative attitudes toward computers, than the other cohorts.

\section{Opportunities for training and development provided by this project}

The PI has improved his skills in Multisim and LabVIEW in such a way that he uses these two software packages in his teaching and laboratory experiments demonstrations. Students are able to understand complex concepts in an easy and visual way. Circuit designs can be done very quickly and immediately see the result using Multisim.

Students have learned valuable skills such as team work, designing an electronic circuit, effective use of the Internet in locating needed information, how to computer simulate an experiment using virtual instruments, interface the LabVIEW program with Multisim to compare actual values with the simulated ones, and troubleshoot a hardwire circuit by using the skills learned in Multisim.

As a result of this project the software drivers needed to interface LabVIEW with Multisim have been developed. This software is required to establish the communication of students' lab experiments measurements with the ones obtained by the instructor. In this way students can get any necessary assistance.

\section{Contribution of this project to the disciplines of Technology and Engineering}

This project contributed to the learning/teaching process in Technology and Engineering programs because its content addressed issues regarding the learning styles on how minorities learn and interact with other students, hands-on activities at a distance because students have 
access to an electronics kit containing all the needed devices and components as well as portable instruments to build, test and troubleshoot ten laboratory experiments related to control systems. The students can reuse these materials to perform other experiments related to control systems and industrial electronics as well as design and build a control system project. Many electronics courses include a laboratory or hands-on component, so it is challenging to develop the complete course through distance education. This project used Multisim and LabVIEW: these two programs allowed students to complete ten laboratory experiments at a distance and send the measurement results to the instructor for assistance and grading purposes.

The interface between Multisim and LabVIEW can be applied to other fields outside technology and engineering. Any field that requires students to perform experiments such as Physics and Chemistry can benefit from this interface. For instance, students can perform a physics experiment at another institution and send their measurement results through the Internet. The instructor then compares these students' measurements with the correct ones using this interface between Multisim and LabVIEW. Students can get then immediate feedback either by pinpointing where the problem area is or receive a grade.

Underrepresented students benefit the most from this project. As mentioned before, this project considers the learning styles of minorities. Minority students were encouraged all the way along this course because they saw results and they learned by doing. They got very excited because they performed the experiments without following a strict sequence. They were allowed to use their previous knowledge and ingenuity to achieve the result when needed. They maintained their interest in every experiment knowing that if they got stuck they just needed to send the measurements and the instructor would provide the needed assistance. When these students saw the results, they became interested in pursuing careers in science, engineering and technology.

\section{Conclusion}

One question being investigated in this study was the impact over time on attitudes and interest in electronics among the project participants. One question from the SALG, "How much of the following (understanding the main concepts) do you think you will remember and carry with you into other classes or aspects of your life?", addresses this issue. the results from this question would suggest that the 2005 and 2006 cohorts of students believe that the concepts they learned in the Tech 167 class will stay with them longer than the 2004 baseline cohort of students believes.

The results from two other questions on the SALG asking students how much the class had increased their understanding or skills would suggest likewise. The skills on which the students assessed their learning go beyond the subject matter and are ones which are likely to transfer to other subjects and contexts as well.

It also seems clear, from the general responses provided by the students in all three years, that the Tech 167 course was an enjoyable and beneficial experience for them.

Distance learning can benefit students who are geographically separated from instruction. This type of learning approach allows a student to learn at his/her own pace. In addition, students are 
immersed in the environment where new technologies in computer simulation and multimedia are common. Underrepresented groups of students, either because of their language difficulties or lack of previous preparation and educational experiences, have the most to benefit from this asynchronous and interactive simulation course.

Distance learning holds strong promise with the proliferation of the Internet and the ongoing development of multimedia courseware. Funded by the $\mathrm{NSF}^{27}$, these lab experiments were developed by the integration of LabVIEW, Multisim, and SC-2075 data acquisition for online laboratory courseware for students to learn in a distance learning environment.

Although the benefits of a virtual educational community are evident, there are some limitations in the application of the virtual laboratory as follows:

1. More self discipline and motivation from students are required than in a traditional class.

2. There is less face to face interaction between students and the instructor.

3. Communication between the instructor and students is not immediate.

4. Students have to understand new contents: LabVIEW, Multisim, 7SC-2075 device for virtual laboratory.

5. Requires initial preparation time on the part of the teacher and there is also the initial setup cost.

Distance teaching can be immediately applicable to technology and engineering courses specifically related to control systems. And the interface between Multisim and LabVIEW can widely be applied to other disciplines beyond engineering and technology.

\section{Acknowledgements}

This study was possible thanks to a grant funded by the National Science Foundation (NSF). NSF Grant Integration of Computer-Based Electronics Laboratory into a Control Systems Course in Electronics Technology, CCLI award 0411330

\section{BIBLIOGRAPHY}

1 Fisher, S. \& Nygren, T. I. (2000). Experiments in the Cost-Effective Uses of Technology in Teaching: Lessons from the Mellon Program So Far. New York: The Andrew W. Mellon Foundation Cost-Effective Uses of Technology in Teaching (CEUTT) Initiative. Available: http://www.ceutt.org/ICLT\%20CEUTT.pdf

2 National Science Foundation, Division of Science Resources Statistics (2002). The Application and Implications of Information Technologies in Postsecondary Distance Education: An Initial Bibliography, NSF 03-305, Project Director, Eileen L. Collins (Arlington, VA 2002). Available: http://www.nsf.gov/sbe/srs/nsf03305/htmstart.htm

3 Shiratuddin, N., Hassan, S., \& Landoni, M. (2003). A Usability Study for Promoting eContent in Higher Education. Educational Technology \& Society, 6 (4), 112-124, Available at http://ifets.ieee.org/periodical/6_4/11.pdf

4 Sharer, D. L., \& Frisbee, M. D. (2003). Don't just tell me, show me! Presenting a microelectronics courses completely on the Internet. ASEE Annual Conference Proceedings. Available: http://www.asee.org/conferences/caps/document/2003-1683_Final.pdf 
Wang, J. Y. (2003). LabView in Engineering Laboratory Courses. $33^{\text {rd }}$ ASEE/IEEE Frontiers in Education Conference Proceedings (November 5-8, Boulder, CO). Available: http://fie.engrng.pitt.edu/fie2003/papers/1400.pdf Biner, P., and R. S. Dean. 1997. Profiling the successful tele-education student. Distance Educator, 1:1-3. Guglielmino, P. J., and L. M. Guglielmino. 2001. Learner Characteristics Affecting Success in Electronic Distance Learning. Paper presented at the $15^{\text {th }}$ Annual Self-Directed Learning Symposium, Boynton Beach, FL, February 2001.

9 Cohen, M. S., \& Ellis, T. J. (2002). Developing a criteria set for an online, distance education environment. ASEE/IEEE Frontiers in Education Conference, Boston, MA.

10 Kubala, T. (1998, March). Addressing student needs: Teaching on the Internet. T.H.E. Journal Online.

11 Lake, D. (1999). Reducing isolation for distance students: an On-Line initiative. Open Learning, 14(3), $14-$ 23.

12 Lee, C. (1996). An active learning mode for laboratory education. ASEE Annual Conference Proceedings. Available: http://www.asee.org/conferences/search/01138.pdf

13 Sumali, H. (2002). An Instrumentation and Data Acquisition Course at Purdue University. ASEE Annual Conference Proceedings. Available: http://www.asee.org/conferences/caps/document/2002-1855_Paper.pdf Crist, S. C. (2001). A Laboratory-Based Instrumentation Course for Non-EE Majors. ASEE Annual Conference Proceedings. Available: http://www.asee.org/conferences/search/20385.pdf Annual Conference Proceedings. Available: http://www.asee.org/conferences/caps/document/200229_Paper.pdf

16 Chen, C. (1998). Using LabVIEW in Instrumentation and Control Course. ASEE Annual Conference Proceedings. Available: $\underline{\mathrm{http}} / / / \mathrm{www}$. asee.org/conferences/search/00612.pdf

17 Chickamenahalli, S. A., Nallaperumal, V., and Waheed, V. (1998). Labview based electric machines laboratory instrumentation. ASEE Annual Conference Proceedings. Available: http://www.asee.org/conferences/search/00355.pdf Krygowski, F. R. (2001). Modernizing a Physical Measurements Laboratory in Engineering Technology. ASEE Annual Conference Proceedings. Available: http://www.asee.org/conferences/search/00695_2001.PDF

19 Yousuf, A. (2001). Data Acquisition Laboratory. ASEE Annual Conference Proceedings. Available: http://www.asee.org/conferences/search/00194_2001.PDF

20 Sheppard, K., Carlucci, D., Carr, R., Corradeschi, T., Messano, A., \& Natiello, L. (2003). Teaching electronics and instrumentation through an innovative core design laboratory in sophomore year.

Proceedings of the 2003 ASEE Annual Conference. Available: http://www.asee.org/conferences/caps/document/2003-2333_Final.pdf

21 Hackworth, J. R., \& Stanley, W. D. (2001). An upper-division virtual laboratory in linear electronics. ASEE Annual Conference Proceedings. Available: http://www.asee.org/conferences/search/01067_2001.PDF Hall, T. M. (2000). Using software for electronics engineering technology laboratory instruction. ASEE Annual Conference Proceedings. Available: http://www.asee.org/conferences/search/20674.pdf Flores, B. C., \& Fabela, R. J. (2002). A concept inventory to probe student understanding of basic electronics. ASEE Annual Conference Proceedings. Available: http://www.asee.org/conferences/caps/document/2002-1889_Paper.pdf Seymour, E., Wiese, D. J., Hunter, A., \& Daffinrud, S. (2000). Creating a Better Mousetrap: On-line Student Assessment of their Learning Gains. Paper originally presented to the National Meetings of the American Chemical Society Symposium, "Using Real-World Questions to Promote Active Learning," San Francisco, March 27, 2000. Available: http://www.aacu-edu.org/SENCER/pdfs/Mousetrap.pdf http://www.csudh.edu/psych/TechnophobiaMeasurementExamCopies.htm Weil, M.M. \& Rosen, L.D. (1998). TechnoStress: Coping With Technology @WORK @HOME @ PLAY. New York: John Wiley \& Sons.

27 NSF Grant Integration of Computer-Based Electronics Laboratory into a Control Systems Course in Electronics Technology, CCLI award 0411330, \$99,521. This project is creating online lecture and laboratory materials for Tech 167—Control Systems, an upper division electronics course. 


\section{ADDENDA \\ Computation of Composite Scores for GATCS, CARS, and CTS}

Each of the five possible responses for each question was assigned a value according to the manual "Measuring Technophobia" by Larry Rosen and Michelle Weil. For the CARS test, all the questions were scored the same. For the GATCS and CTS tests, questions were scored differently depending on whether they were phrased "in the negative direction" or "in the positive direction".

Then, the number of students giving a response was multiplied by the corresponding value for that response. Calculations for each of the possible responses were totaled to give a cumulative score for each question. The cumulative scores for all questions were summed to give a composite total score for the survey. In order to compare composite scores for 2004 with 2005 and 2006, the 2005 and 2006 scores were multiplied by weighting factors of 1.28 and 1.64 , respectively. This is 41 (number of students taking the 2004 test) divided by 32 and 25 (the number of students taking the 2005 and 2006 CARS tests, respectively). 